\title{
Methods of studying the characteristics of hydraulic systems of loading machines on a laboratory hydraulic stand
}

\author{
Yuri Ezhov 1.* ${ }^{1 .}$ Igor Zub, Natalia Pizhurina, and Vladimir Sidorenko \\ ${ }^{1}$ Admiral Makarov State University of Maritime and Inland Shipping, 5/7, Dvinskaya str, Saint- \\ Petersburg, Russia, 198035
}

\begin{abstract}
The operation of loading machines requires special attention in the selection of materials for hydraulic devices and the development of recommendations for their operation. Competencies that should be obtained by a specialist operating the handling equipment, include the ability to analyze the operation of the hydraulic system on the basis of these devices and adjust the operating modes of the handling devices. In this paper, a number of experiments on the hydraulic bench. During the experiments, the characteristics of the pressure dependence in the lifting cylinder on the weight of the load and the lifting angle were removed. The considered algorithm of research can be used in the development of methods of laboratory work for the training of specialists in the field of operation and design of loading equipment.
\end{abstract}

\section{Introduction}

Training of specialists in the direction of "Operation of transport and technological machines and complexes" is impossible without studying the hydraulic systems used on loading devices operating in sea and inland ports. Different geographical location of ports, year-round navigation lead to the need to operate the handling equipment in different conditions, including at low temperatures.

Thus, for the development of the regions of the Far North and the Northern sea route, the main strategic directions are planned [1], for the implementation of which the state subsidizes the construction of new ports, icebreaking vessels, rescue and auxiliary fleets, as well as coastal infrastructure.

At low ambient temperatures, the viscosity and density of the hydraulic fluid increases, at the same time, the gaps in the joints increase, which leads to increased friction forces in the hydraulic equipment, and as a result, increased wear and failure of the hydraulic equipment.

Failures of parts and components of hydraulic systems are due to insufficient frost resistance of the materials used. This applies to both the metals from which the hydraulic cylinders are made, and materials on a synthetic basis and rubber products (seals and hoses of the hydraulic system). At low temperatures, the elasticity of the seals decreases, when the

\footnotetext{
*Corresponding author: ezhovye@gumrf.ru
} 
temperature reaches a temperature fluctuation, moisture is frozen out in microcracks, which leads to the freezing of the seals to the details [2]. In such cases, there is a destruction of the seal, and, as a consequence, the loss of performance. In [3, 4] considered simulation model, the hydraulic overload devices. By decomposing a simulation model built through Petri nets,it is possible to determine why the system and the particular node are not functioning.

When the temperature of hydraulic oil is reduced, the hydraulic system pressure may exceed the maximum allowable, which leads to large internal stresses and, as a result, to brittle fracture [5]. The most dangerous are the starting moments of the hydraulic drive at low temperatures, when the pressure increases 10 times or more compared to the pressure at normal temperatures [6]. The increase in the viscosity of hydraulic oil leads to an increase in hydraulic losses, the deterioration of lubrication of conjugated parts of hydraulic equipment, which leads to a decrease in the life of parts and the hydraulic system as a whole.

When the viscosity of the hydraulic oil increases, vacuum occurs on the suction hydraulic line, the rate of gas release dissolved in the oil decreases, which leads to foaming during the operation of the hydraulic system. The presence of gases in the hydraulic oil is one of the causes of cavitation arising in the elements of the hydraulic system. In addition, the occurrence of cavitation depends on the physical properties of the liquid and flow parameters (pressure, temperature, speed) [7].

The most frequent emissions of hydraulic oil from-for breaks of the high pressure sleeves (RVD) [6] or seals. The length of the RVD on modern loading devices is several tens of meters, with the breakthrough of one of the sleeves, the equipment fails. In work [8] the design of RVD containing a carbon fiber thread as a reinforcing element is offered that increases mechanical strength at bending influences.

Some hydraulic systems in forklifts and mobile cranes have small section (1/4-3/8 inch) and long (2-4 meters) metal pipes, which contributes to the cooling of hydraulic oil, and at low temperatures can lead to the failure of hydraulic engines. This is due to the fact that the moisture contained in the hydraulic oil, creates an ice plug, even with a small break in the work at low temperatures. The minimum temperature of the hydraulic oil, wherein the loader has hydraulic drive can start a movement of $+20^{\circ} \mathrm{C}$.

To build a mathematical model of pressure in the hydraulic system, restrictions are introduced: by temperature tgs $\rightarrow$ min and pressure in the hydraulic system Pgs $\rightarrow$ max. The last parameter depends on a number of variables:

$$
\operatorname{Pgs}=f(v, h, d s, q)
$$

where $\mathrm{v}$ - is the viscosity of the hydraulic oil, $\mathrm{h}$ - is the gaps in the conjugate connections, ds - is the diameter of the flow section of the RVD, $\mathrm{q}$ - is the load on the hydraulic system.

The operating temperature of the hydraulic system (tgs) is measured on the interval [tmin, tmax]. As mentioned above, the minimum temperature at which the equipment starts to work, having a hydraulic drive, is $+20^{\circ} \mathrm{C}$. For other types of hydrophobic devices, tmin can take different values, depending on the type of hydraulic oil used.

To calculate the required strength of the RVD and other elements of the hydraulic system, it is necessary to take into account the maximum pressure of the hydraulic oil $p_{\max }$, achieved in the hydraulic system under all possible operating conditions.

The professionals involved in the working condition of hydraulic systems of various types of mechanisms must be able to determine the operating characteristics and on the basis of their analysis to adjust the mode of operation of the equipment. For realization of this task in educational process the complex of laboratory works [9] is developed, carried out on the hydraulic stand by the students studying in the directions connected with operation of transport and technological machines and mechanisms. 
The results of laboratory studies on the stand simulating the hydraulic system of the handling equipment obtained under different operating conditions are discussed below (Fig. 1).

During the experiment, the dependence of the oil pressure $\mathrm{p}$ in the hydraulic cylinder of the boom lift on 3 values: the mass of the load $m$, the boom departure 1 and the boom lift angle $\alpha$ was studied. A series of measurements of the oil pressure value depending on the boom angle $\alpha$ was made with the variation of the other 2 variables (parameters): $t$-mass of the load and 1 - boom departure. In this series, the specified dependence was studied for three values of the parameter $\mathrm{m}$ - weight of the load $(20,30$ and $40 \mathrm{~kg})$, and for each of these 3 values, pressure measurements were made at 3 values of the parameter l-boom departure (1minimum flight, 2 - boom departure $250 \mathrm{~mm}, 3$ - maximum flight $500 \mathrm{~mm}$ ).

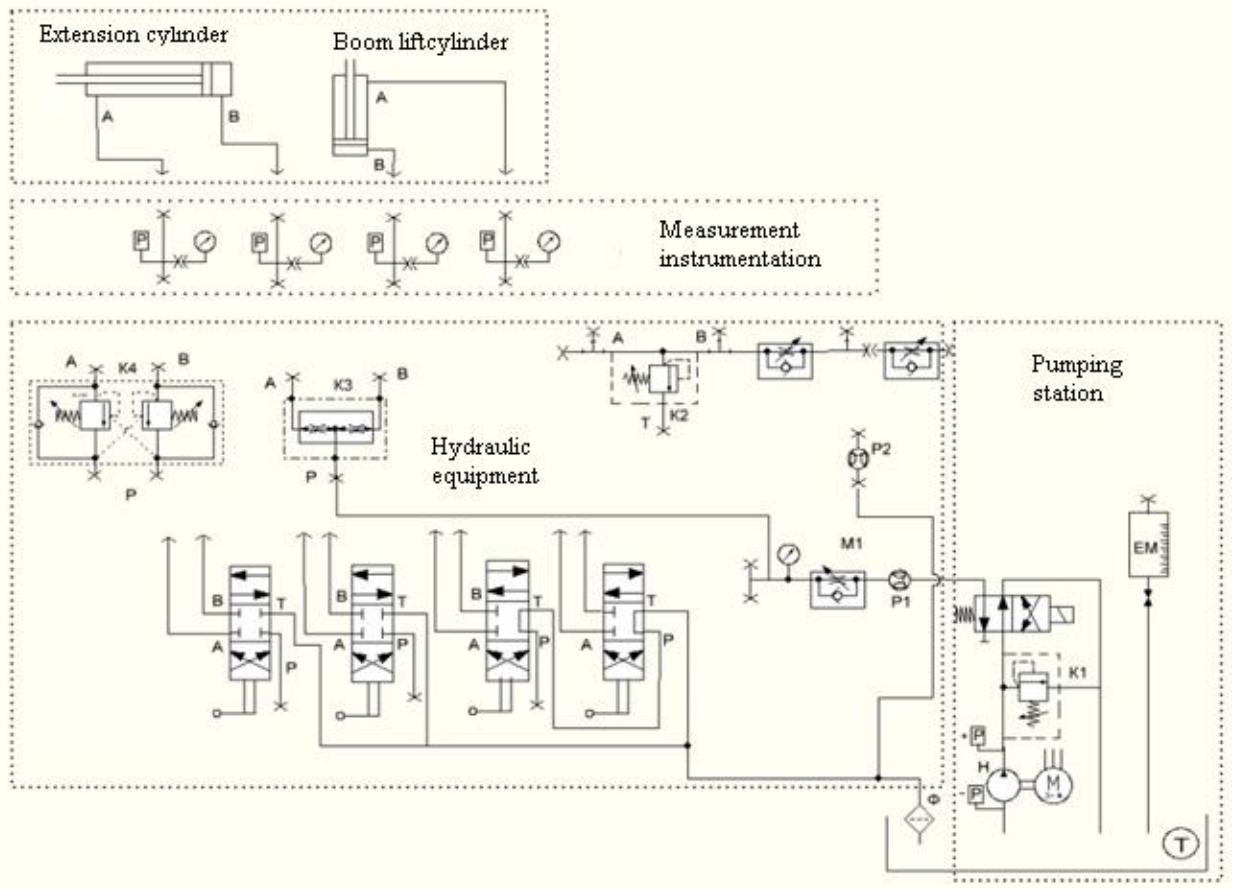

Fig. 1. Scheme of the hydraulic stand.

Fig. 2-4 show typical graphs of the pressure of the hydraulic oil from the lifting angle of the boom. Each point of the graph is obtained as the average of a series of seven dimensions. The accuracy of measurements was estimated by the method of confidence intervals. The obtained experimental dependences are approximated by the 2 nd degree polynomial in the statistical processing program Statgraphics. The graphs show the accuracy of the approximation. From the comparison of the error (accuracy) of the approximation with confidence intervals, we can conclude about the statistical significance of the obtained nature of the dependence. 


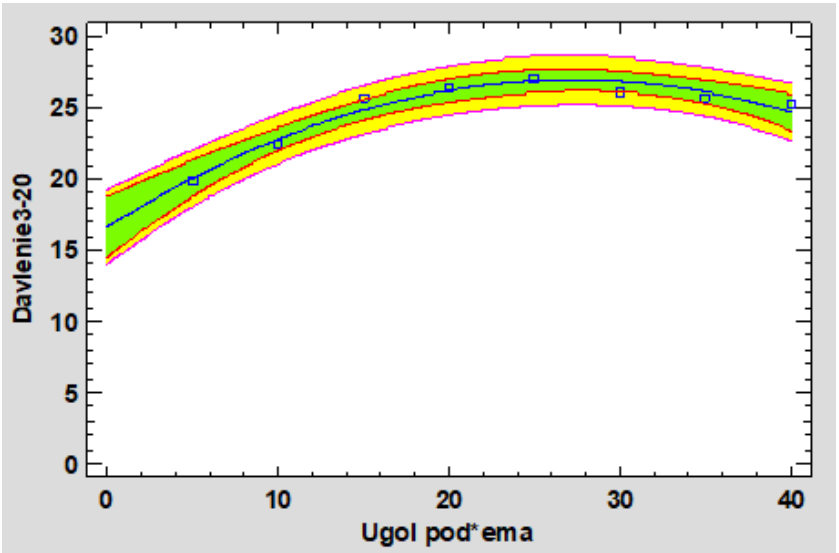

Fig. 2. The graph of the pressure in the hoist cylinder from the angle of the boom (the boom $500 \mathrm{~mm}$, weight $20 \mathrm{~kg}$ ).

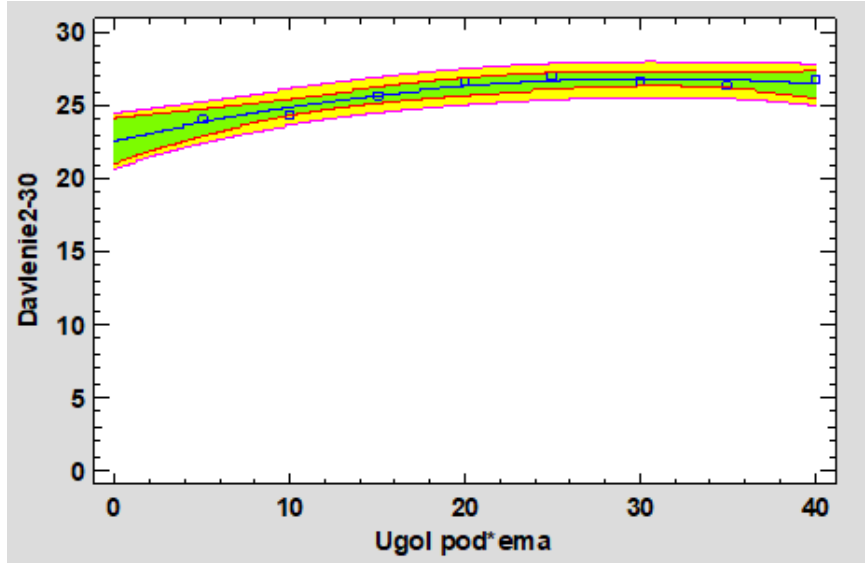

Fig. 3. The graph of the pressure in the hoist cylinder from the angle of the boom (the boom $500 \mathrm{~mm}$, weight $30 \mathrm{~kg}$ ).

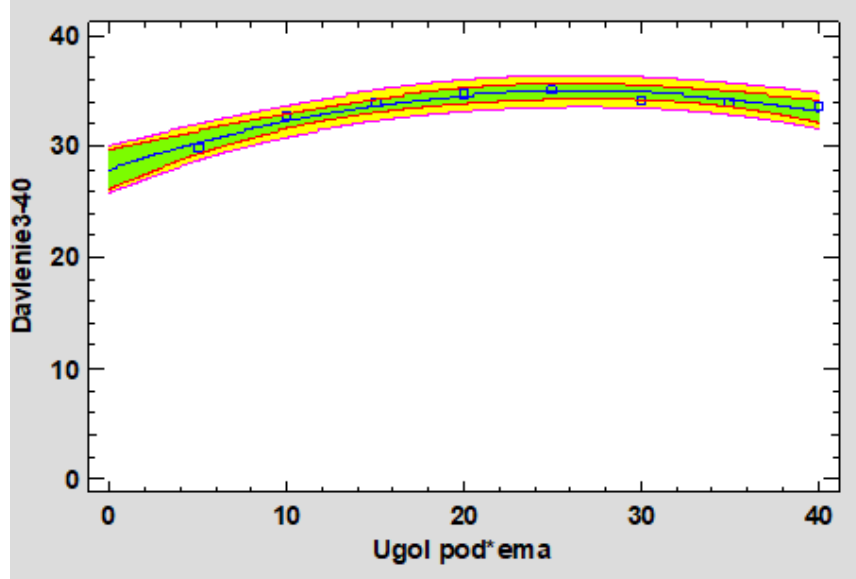

Fig. 4. The graph of pressure dependence in the lifting cylinder on the boom lifting angle (boom reach $500 \mathrm{~mm}$, weight of the load $40 \mathrm{~kg}$ ). 
The analysis of the obtained laboratory results shows that the calculation of the strength characteristics of the RVD and other elements of the hydraulic system can not be based on the values of the hydraulic oil pressure at the maximum values of the parameters $\mathrm{m}, 1$ and $\alpha$. It is necessary to consider the nonlinear dependence of the pressure of the hydraulic oil from the lifting angle of the boom, namely to consider the possibility of the presence of a local maximum.

Thus, on the basis of the obtained results, the following algorithm for determining the maximum pressure of pmax oil in the hydraulic system of the handling equipment can be proposed:

1. The values of the parameters $m$ and 1 to determine as the maximum values of the load capacity and departure of the boom.

2. To measure the experimental dependence of the oil pressure $p$ on the boom lift angle at these values of the parameters $m$ and 1 . It is necessary to ensure the statistical significance of the results. To do this, make several (at least 5) measurements at one point and estimate the confidence intervals.

3. Approximate the obtained dependence by a polynomial. Determine the point of the local maximum $\alpha_{0}$ (the value of the angle at which the maximum is observed).

4. Take the nearest to this point the experimental value of the angle $\alpha$. The required maximum pressure value $p_{\max }$ is defined as the upper (right) boundary of the corresponding confidence interval.

He proposed algorithm can be used in the development of methods of laboratory work on a hydraulic stand that simulates the hydraulic system of the handling equipment. With regard to its transfer to real conditions, it is necessary to investigate the simulation of hydraulic real reloading devices in the laboratory.

\section{References}

1. URL: http://www.rg.ru/2009/03/30/arktika-osnovy-dok.html

2. A. M. Ishkov, Theory and practice of reliability engineering in the North (Yakutsk, SB RAS, 2004)

3. I. V. Zub, River transport (XXI century) 4, 52 - 58 (2016)

4. S. Sokolov, Journal of Engineering Science and Technology Review. 9 (5) 176 - 181 (2016)

5. N. Maslov, Vestnik of the Siberian state University of Railways, 1, 5 - 15 (2016)

6. N. Y. Klinduh, PhD Thesis (Tomsk, Siberian Federal University, 2007)

7. I. Piersol, I. Cavitation (Moscow, Mir, 1975)

8. A. V. Yarkin, Engineering journal of don, 3 (2014)

9. I. V., Zub, Yu. E. Ezhov, N. Yu. Ivanov Hydraulic drive of transport and transporttechnological machines and equipment. (SPb, GUMRF named after Admiral S. O. Makarov, 2018) 